\title{
Preparation and Properties of Biodegradable Film Composites Using Modified Cellulose Fibre-Reinforced with PVA
}

\author{
Sandeep S. Laxmeshwar, ${ }^{1}$ D. J. Madhu Kumar, ${ }^{2}$ S. Viveka, ${ }^{2}$ and G. K. Nagaraja ${ }^{2}$ \\ ${ }^{1}$ Post-Graduate Department of Studies and Research in Polymer Science, Sir, M. V. PG Centre, University of Mysore, \\ Mandya 571402, Karnataka, India \\ ${ }^{2}$ Post-Graduate Department of Studies and Research in Chemistry, Mangalore University, Mangalagangothri, \\ Mangalore 574199 Karnataka, India \\ Correspondence should be addressed to G. K. Nagaraja, nagarajagk@gmail.com
}

Received 18 December 2011; Accepted 5 January 2012

Academic Editors: S. Ifuku, B. Kiskan, and D. Radic

Copyright (C) 2012 Sandeep S. Laxmeshwar et al. This is an open access article distributed under the Creative Commons Attribution License, which permits unrestricted use, distribution, and reproduction in any medium, provided the original work is properly cited.

\begin{abstract}
Cellulose has a potential to become a key resource in the development of biodegradable film composites. In this work, cellulose was modified by using 2-(Trifluromethyl)benzoylchloride by base-catalyzed reaction. Modification of cellulose was confirmed by IR studies. The biodegradable composite films were developed by film casting method using modified cellulose with Poly(vinyl alcohol) in different compositions. The film composites were characterized by mechanical, moisture absorption, gas barrier, and biodegradable properties. Obtained films have shown transparency and flexibility and displayed good mechanical properties. Film composites also showed good biodegradability. Better barrier properties showed by film composites as the percentage of modified cellulose increased. This indicates the importance of modified cellulose as a reinforcing agent. After evaluating these properties of film composites, we came to conclusion that these biocomposites can be used to membrane and packaging applications.
\end{abstract}

\section{Introduction}

Recently, cellulose-based composites have come to the attention of researchers becauseof the numerous advantages which these renewable fibres represent. Cellulose is one of the most abundant biopolymers in nature and estimated to be at levels approaching $10^{11}$ tons annually. Furthermore, cellulose is considered to be one of the most promising renewable resources and an environmentally friendly [1-4] alternative to products derived from the petrochemical industry. Plant-derived cellulose has been widely used as either reinforcement. Recently, modified cellulose has been used as reinforcements for various composites due to its excellent mechanical performance and fully biodegradable in a wide variety of environmental conditions. As a result, various cellulose-based composites have been prepared. Chemical modification of cellulose [5-8] is an important route for the production of multifunctional materials.

Even though, cellulose has not reached its potential application in many areas because of its infusibility and insolu- bility; but at the same time, cellulosic fibres are hygroscopic in nature; moisture absorption can result in swelling of the fibres which may lead to microcracking of the composite and degradation of mechanical properties. This problem can be overcome by treating these fibres with suitable chemicals to decrease the hydroxyl groups which may be involved in the hydrogen bonding within the cellulose molecules. Chemical treatments may activate these groups or can introduce new moieties that can effectively interlock with the matrix. A number of fibre surface treatments like silane treatment, benzoylation, and peroxide treatment were carried out which may result in improved mechanical performance of the fibre and composite. By limiting the substitution reaction on the surface of the fibres, good mechanical properties were obtained and a degree of biodegradability was maintained. As a result, various cellulose-based composites have been prepared. The aim of this work is to produce high strength biodegradable film composites, which can be useful for membrane and packaging applications. For this, we have to choose one polymer. However, there is no literature 


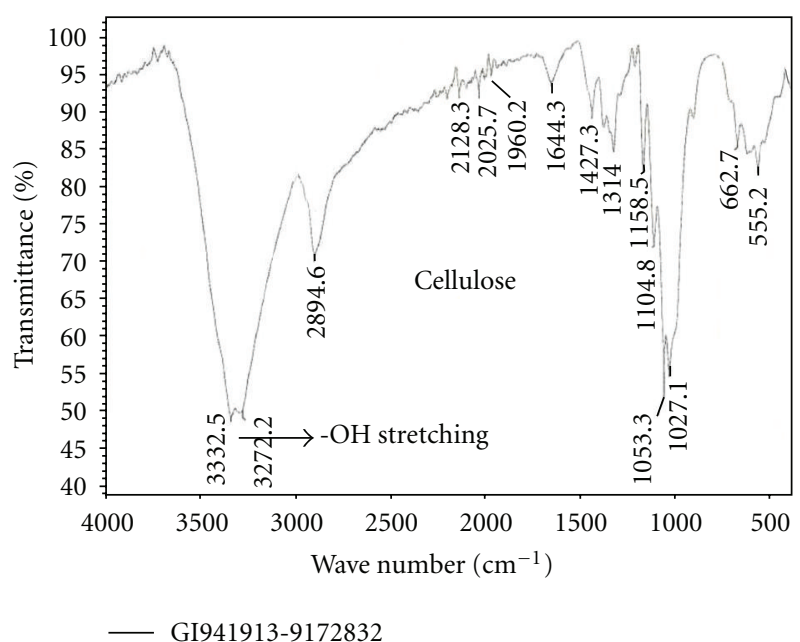

FIGURE 1: IR spectra of cellulose.

regarding the combination of modified cellulose and poly(vinyl alcohol) [9] which has excellent mechanical properties and processing capabilities. Up to know, there is no information on mechanical properties, moisture absorption, and environmental biodegradability of the modified cellulose/poly(vinyl alcohol) composite has been reported. In this work Modified cellulose/poly(vinyl alcohol) biocomposites were developed by a solution casting method.

\section{Experimental Section}

2.1. Materials. The fibre used in this work was commercial microcrystalline cellulose supplied by Loba Chemie. 2-(Trifluromethyl)benzoylchloride and Pyridine were purchased from Aldrich and used as received. Poly(vinyl alcohol) (PVA) was obtained from Fluka AG (Switzerland). The composite films were developed using Magic mould releasing agent and with Teflon mould of one square feet with $3 \mathrm{~mm}$ depth. The solvent acetonitrile was purchased from Rankem and used with purification. Finally, the composite films were air dried in hot air oven.

2.2. Modification of Cellulose. Cellulose was treated with sodium hydroxide solution at room temperature and stirred for 2 hrs. Then, solid obtained was filtered off. Salt formation was confirmed by solubility test, since it is freely soluble in water. This salt was treated with 2-(Trifluromethyl)benzoylchloride in presence of pyridine as a base cum solvent and stirred overnight at $100^{\circ} \mathrm{C}$. Then, dumped into water; solid obtained was filtered off. This product was confirmed by IR analysis, which shows the absence of peak at 3332 reciprocal centimeter. Figures 1 and 2 represent the IR spectra of cellulose and modified cellulose.

2.3. Preparation of Films. Modified cellulose of 2-(Trifluromethyl) benzoylchloride was taken in water and acetonitrile with Poly(vinyl alcohol) in different composition like 10:90, $20: 80,30: 70,40: 60,50: 50,60: 40,70: 30,80: 20,90: 10$, and $95: 05$ ratios [10-14]. The reaction mixture was heated to $100^{\circ} \mathrm{C}$ for $24 \mathrm{hrs}$. After $24 \mathrm{hrs}$, the reaction mass was

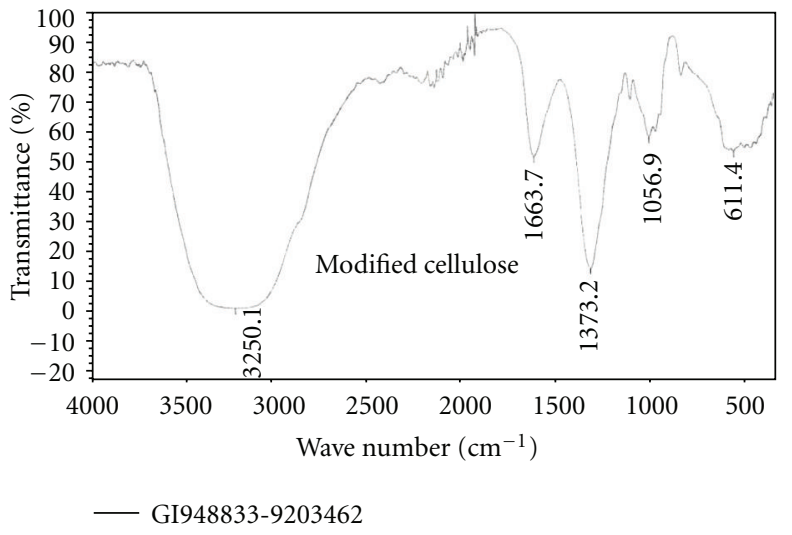

FIGURE 2: IR spectra of modified cellulose.

turned to viscous state, it was allowed to room temperature and spread on the Teflon mould which was sprayed before by mould releasing spray and dried under vacuum oven at $100^{\circ} \mathrm{C}$ to remove water contents completely. After complete drying, the films are stored in moisture free environment.

2.4. Soil Burial Degradation Experiments. Biodegradation experiments [15-18] were carried out at ambient temperature under moisture-controlled conditions. Specimens of each composite were placed in a series of perforated boxes containing moisturized soil. The specimens $(40 \times 10 \mathrm{~mm})$ were buried $150 \mathrm{~mm}$ beneath the surface of soil which was regularly moistened with distilled water. The samples were removed at predetermined time points, washed with water several times in order to ensure the stop of the degradation, dried at room temperature to a constant weight, and then were stored in darkness until testing. The specimens were weighed on the PGB200 model analytical balance in order to determine the average weight loss as follows:

$$
\text { weight loss }=\frac{W o-W t}{W o} \times 100,
$$

where $W o$ is the initial mass and $W t$ is the remaining mass at any given time, $t$. All results are the average of three replicates.

2.5. Moisture Absorption Experiments. Water uptake measurements [19] were performed under 75\% RH (relative humidity) at $22^{\circ} \mathrm{C}$. All the specimens for moisture absorption experiments with dimensions of $40 \mathrm{~mm}$ by $10 \mathrm{~mm}$ were cut from composite sheets. Before the absorption experiments, specimens were thoroughly washed and then vacuum dried until a constant weight was attained. At predetermined intervals, specimens were taken out from the chambers and weighed using a PGB200 model analytical balance (with a precision of $0.1 \mathrm{mg}$ ).

The moisture uptake at any time points as a result of moisture absorption was determined as follows:

$$
\text { moisture uptake }=\frac{W h-W o}{W o} \times 100,
$$

where $W h$ and $W o$ denote weight of humid specimens and the original dry value (the initial weight of films prior to 
TABLE 1: Biodegradable studies of ten film composites.

\begin{tabular}{lcccccccccc}
\hline No. of days & $\begin{array}{c}\text { \%wt. } \\
\text { decrease } \\
10: 90\end{array}$ & $\begin{array}{c}\text { \%wt. } \\
\text { decrease } \\
20: 80\end{array}$ & $\begin{array}{c}\text { \%wt. } \\
\text { decrease } \\
30: 70\end{array}$ & $\begin{array}{c}\text { \%wt. } \\
\text { decrease } \\
40: 60\end{array}$ & $\begin{array}{c}\text { \%wt. } \\
\text { decrease } \\
50: 50\end{array}$ & $\begin{array}{c}\text { \%wt. } \\
\text { decrease } \\
60: 40\end{array}$ & $\begin{array}{c}\text { \%wt. } \\
\text { decrease } \\
70: 30\end{array}$ & $\begin{array}{c}\text { \%wt. } \\
\text { decrease } \\
80: 20\end{array}$ & $\begin{array}{c}\text { \%wt. } \\
\text { decrease } \\
90: 10\end{array}$ & $\begin{array}{c}\text { \%wt. } \\
\text { decrease } \\
95: 05\end{array}$ \\
\hline 2 & 2.4 & 2.7 & 3.1 & 2.8 & 2.9 & 3.1 & 2.9 & 3.2 & 3.4 & 3.3 \\
4 & 3.6 & 3.8 & 4.4 & 3.8 & 3.9 & 4.2 & 3.7 & 4.2 & 4.6 & 4.3 \\
6 & 5.6 & 5.7 & 5.8 & 5.7 & 5.8 & 5.7 & 5.5 & 5.7 & 5.7 & 5.7 \\
8 & 7.5 & 7.4 & 7.6 & 7.8 & 7.5 & 7.7 & 7.7 & 7.6 & 7.9 & 7.9 \\
10 & 9.4 & 9.7 & 9.7 & 9.4 & 9.8 & 9.6 & 9.6 & 9.8 & 9.9 & 9.8 \\
12 & 11.9 & 11.8 & 11.9 & 11.9 & 11.5 & 11.6 & 11.4 & 11.8 & 11.7 & 11.8 \\
14 & 13.7 & 13.7 & 13.6 & 13.7 & 13.6 & 13.8 & 13.8 & 13.6 & 13.8 & 14.1 \\
16 & 15.7 & 15.9 & 15.6 & 15.9 & 15.7 & 15.7 & 15.8 & 15.7 & 15.9 & 15.7 \\
18 & 16.6 & 16.8 & 16.7 & 16.9 & 16.5 & 16.6 & 16.8 & 16.8 & 16.6 & 16.9 \\
\hline
\end{tabular}

exposure to moisture absorption), respectively. All data from three repeated tests were averaged.

2.6. Mechanical Testing. Mechanical properties were measured according to the ASTM standard method D882-test method A (ASTM 1997) with application of a Lloyd universal tensile machine with a $5 \mathrm{KN}$ capacity at $25 \pm 2^{\circ} \mathrm{C}$ and $55 \pm$ $5 \% \mathrm{RH}$. The initial gauge separation and cross-speed were set to $50 \mathrm{~mm}$ with $25 \mathrm{~mm} / \mathrm{min}$, respectively. Test specimens with a length of $40 \mathrm{~mm}$ and a width of $10 \mathrm{~mm}$ were cut from composite sheets. All specimens were equilibrated in a chamber kept at $25^{\circ} \mathrm{C}$ and $40 \%$ relative humidity for $24 \mathrm{hr}$ before testing. All these tests were conducted at ambient temperature and an average value of three repeated tests was taken for each material.

2.7. Oxygen Permeability Test. The oxygen transmission rate was determined in accordance with ASTM D3985 (ASTM 1995). Oxygen permeability was calculated by the multiplication of the OTR at steady state by the average film thickness divided by the partial pressure difference between the two sides of the film. The film samples were equilibrated at $25 \pm$ $2^{\circ} \mathrm{C}$ and $55 \pm 5 \% \mathrm{RH}$ for at least 2 days in a controlledenvironment cabinet containing a saturated magnesium nitrate solution prior to the analysis.

2.8. Water Vapor Permeability Test. The gravimetric modified cup water method based on the ASTM E96-9223 was used to determine water vapor permeability (WVP). Film samples were tested in circular test cups made of polymethylmethacrylate. The fan speeds in the cabinets were set at an air velocity of $175 \mathrm{~m} \mathrm{~min}^{-1}$. The weight loss was monitored until it was certain that water vapor transmission through the film samples had attained a steady state.

2.9. Scanning Electron Microscopy. Scanning electron microscopy (SEM) was used for the evaluation of the film microstructure. Before the analysis, the samples were sputter coated with a thin layer of gold to avoid electrical charging.

\section{Result and Discussion}

3.1. Biodegradation in Soil. In this work, soil burial experiment were performed for all the ten $10: 90,20: 80,30: 70$, $40: 60,50: 50,60: 40,70: 30,80: 20,90: 10$, and $95: 05$ ratio films. The studies on biodegradation behaviour are important for the application of biocomposites in environment. Table 1 presents weight loss of various films as a function of biodegradation time. Note that weight loss shows an approximately linear relation with degradation time for all the ten films. For all the films weight decrease for 2 days is average $3 \%$ and it decreases gradually as the time increases and after 18 days average weight decrease is $17 \%$. Crystalline regions are more difficult to degrade. The ability of films to degrade depends greatly on physicochemical characteristics of the substrate, such as the degree of crystallinity and polymerization of cellulose, of which the crystallinity degree of cellulose is the most important structural parameter. All the ten film composites showed almost same resistance to microorganism attack in the soil. As the microorganism attacks, the composites lose their structural integrity. Undoubtedly, the results obtained herein reveal that the film composites will not cause any deleterious ecological impact. In other words, the film composites are fully biodegradable.

3.2. Moisture Absorption Behaviour. Moisture absorption test was carried for all the ten composite films in which the modified cellulose and matrix polyvinyl alcohol are in the ratio of $10: 90,20: 80,30: 70,40: 60,50: 50,60: 40$, $70: 30,80: 20,90: 10$, and $95: 05$. We observed that as the percentage of modified cellulose increases, moisture absorption decreases. The moisture absorption results are crucial for understanding the performance of cellulose-based composites, since the moisture pickup under immersion in water or exposure to high humidity intimately relates to such composite properties as mechanical strength, dimensional stability, and appearance. Though the polyvinyl alcohol has been considered as one of the most promising materials for biodegradable plastics, its poor resistance to water 
TABLE 2: Moisture absorption studies of ten film composites.

\begin{tabular}{|c|c|c|c|c|c|c|c|c|c|c|}
\hline $\begin{array}{l}\text { No. of } \\
\text { hours }\end{array}$ & $\begin{array}{c}\text { \%wt. } \\
\text { increase } \\
10: 90\end{array}$ & $\begin{array}{c}\text { \%wt. } \\
\text { increase } \\
20: 80\end{array}$ & $\begin{array}{c}\% w t . \\
\text { increase } \\
30: 70\end{array}$ & $\begin{array}{c}\text { \%wt. } \\
\text { increase } \\
40: 60\end{array}$ & $\begin{array}{c}\text { \%wt. } \\
\text { increase } \\
50: 50\end{array}$ & $\begin{array}{c}\text { \%wt. } \\
\text { increase } \\
60: 40\end{array}$ & $\begin{array}{c}\text { \%wt. } \\
\text { increase } \\
70: 30\end{array}$ & $\begin{array}{c}\text { \%wt. } \\
\text { increase } \\
80: 20\end{array}$ & $\begin{array}{c}\text { \%wt. } \\
\text { increase } \\
90: 10\end{array}$ & $\begin{array}{c}\text { \%wt. } \\
\text { increase } \\
95: 05\end{array}$ \\
\hline 2 & 3.0 & 2.8 & 2.7 & 2.4 & 1.8 & 1.7 & 1.6 & 1.5 & 1.4 & 1.4 \\
\hline 4 & 5.3 & 4.9 & 4.8 & 4.5 & 3.8 & 3.5 & 3.5 & 3.0 & 2.8 & 2.7 \\
\hline 6 & 7.1 & 6.8 & 6.6 & 6.1 & 5.5 & 5.0 & 4.9 & 4.4 & 4.2 & 4.1 \\
\hline 8 & 9.0 & 8.7 & 8.4 & 7.8 & 7.1 & 6.5 & 6.4 & 5.9 & 5.6 & 5.5 \\
\hline 10 & 10.7 & 10.4 & 9.8 & 9.1 & 8.3 & 7.6 & 7.4 & 6.9 & 6.5 & 6.3 \\
\hline 12 & 12.1 & 11.8 & 10.8 & 9.9 & 9.1 & 8.4 & 8.0 & 7.5 & 7.0 & 6.7 \\
\hline 14 & 13.8 & 13.4 & 12.1 & 11.2 & 10.3 & 9.5 & 9.0 & 8.5 & 7.9 & 7.5 \\
\hline 16 & 15.7 & 15.3 & 14.5 & 12.5 & 11.4 & 10.7 & 10.1 & 9.4 & 8.7 & 8.2 \\
\hline 18 & 17.4 & 16.9 & 16.0 & 13.8 & 12.7 & 12.0 & 11.2 & 10.4 & 9.7 & 9.1 \\
\hline 20 & 18.5 & 18.0 & 17.0 & 14.7 & 13.5 & 12.8 & 11.8 & 11.0 & 10.1 & 9.4 \\
\hline 22 & 20.3 & 19.7 & 18.5 & 16.2 & 14.9 & 14.1 & 13.0 & 12.2 & 11.2 & 10.3 \\
\hline 24 & 21.3 & 20.6 & 19.8 & 17.5 & 16.0 & 15.2 & 14.1 & 13.1 & 12.0 & 10.9 \\
\hline
\end{tabular}

TABLE 3: Typical tensile properties of ten film composites.

\begin{tabular}{lcccc}
\hline S. no. & Modified cellulose + PVA & Tensile strength $(\mathrm{MPa})$ & Young's modulus $(\mathrm{MPa})$ & Elongation at break $(\mathrm{mm})$ \\
\hline 1 & $10+90$ & 18.36762469 & 720.7569263 & 275.7665531 \\
2 & $20+80$ & 19.00359353 & 742.0972147 & 274.9712453 \\
3 & $30+70$ & 19.56798685 & 759.4714069 & 272.1867043 \\
4 & $40+60$ & 19.62478011 & 789.8828692 & 249.2695623 \\
5 & $50+50$ & 19.9713187 & 807.5349963 & 218.3305132 \\
6 & $60+40$ & 20.12305195 & 851.6004516 & 88.56065012 \\
7 & $70+30$ & 20.54942511 & 875.4536204 & 71.98740953 \\
8 & $80+20$ & 21.16421162 & 893.8736607 & 70.35176481 \\
9 & $90+10$ & 21.23381901 & 1093.200648 & 58.0436579 \\
10 & $95+05$ & 22.41561682 & 1316.185871 & 41.07783552 \\
\hline
\end{tabular}

absorption limits its wide applications. Addition of fillers is an effective way of decreasing its sensitivity to moisture and improving mechanical properties. This behaviour clearly reflects the presence of hydrophobic moieties onto the fiber surface increase in their resistance towards moisture. Table 2 shows the moisture absorption behaviour for all the ten films.

3.3. Mechanical Properties. Tensile properties [20-23] of all the ten $10: 90,20: 80,30: 70,40: 60,50: 50,60: 40,70: 30$, $80: 20,90: 10$, and $95: 05$ ratio films are presented in Table 3 . We observed that tensile strength and Young's modulus of films increase as the percentage composition of the modified cellulose increases. This enhancement indicates the effectiveness of the modified cellulose as reinforcement. However, a decrease in elongation at break is observed as the percentage composition of modified cellulose increases. With the increasing of cellulose content, the interactions between the cellulose and the matrix is improved and crack propagation was inhibited, which resulted in the increased tensile strength and Young's modulus. Contrarily, it illustrated that there was interfacial adhesion between cellulose and the matrix; otherwise, it would result in premature composite failure because the reinforcing cellulose simply pulled out of the matrix without contributing to the strength or stiffness of the material. Figure 3 represents tensile strength of all the films.

3.4. Oxygen Permeability Test. Generally, hydrophilic polymeric films have shown good oxygen barrier property. Table 4 represents OTR (Oxygen Transmission Rate) values for all the ten $10: 90,20: 80,30: 70,40: 60,50: 50,60: 40$, $70: 30,80: 20,90: 10$, and $95: 05$ ratio films. We observed that there is a great decrease in oxygen transmission rate as the percentage composition of the modified cellulose increases. As can be observed in Table 4, there was an improvement in oxygen barrier properties of the films as the percentage of modified cellulose increases. It is obvious that modified cellulose played a powerful role in improving the oxygen gas barrier properties. The increased molecular interaction resulted in a film with compact structure and low OTR value. Oxygen transmission rate increases as the percentage of modified cellulose decreases because intermolecular bonding between fibre and matrix decreases. This resulted in a phase separation among the main components 


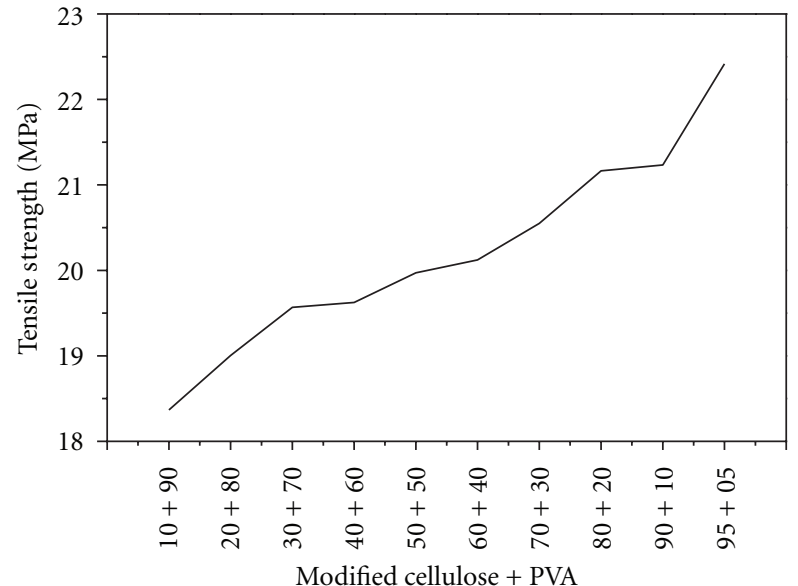

Figure 3: Variation of tensile strength for different film composites.

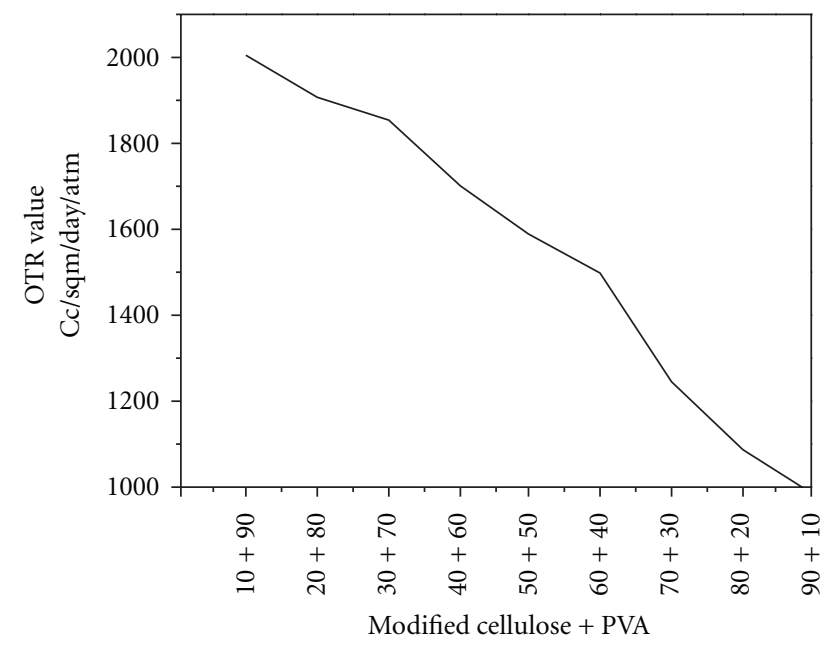

FIGURE 4: Variation of OTR value for different film composites.

where the film could not be formed well, facilitating the oxygen permeation. So, it was more advantageous to improving the gas barrier properties by increasing the percentage of modified cellulose. Figure 4 represents oxygen permeation curves for all the films. This result indicates the potential of these films to be used as a natural packaging to protect food from oxidation reactions.

3.5. Water Vapor Permeability Test. The water vapor permeability of films depends on many factors, such as the integrity of the film, the hydrophilic-hydrophobic ratio, the ratio between crystalline and amorphous zones, and the polymeric chain mobility. Table 5 represents WVTR (water vapor transmission rate) values for all the ten $10: 90,20: 80,30: 70$, $40: 60,50: 50,60: 40,70: 30,80: 20,90: 10$, and $95: 05$ ratio films. We observed that there is a small decrease in water vapor transmission rate as the percentage composition of the modified cellulose increases. This is because as the percentage composition of modified cellulose increases, hydrophilicity of the film decreases. This phenomenon could be related to the significant hydrogen bonding interaction with water.
TABLE 4: Oxygen permeation rate for ten different film composites.

\begin{tabular}{lcc}
\hline S. no. & Modified cellulose + PVA & $\begin{array}{c}\text { OTR value; } \\
\text { cc/sqm/day/atm }\end{array}$ \\
\hline 1 & $10+90$ & 2005 \\
2 & $20+80$ & 1907 \\
3 & $30+70$ & 1854 \\
4 & $40+60$ & 1701 \\
5 & $50+50$ & 1589 \\
6 & $60+40$ & 1498 \\
7 & $70+30$ & 1245 \\
8 & $80+20$ & 1087 \\
9 & $90+10$ & 987 \\
10 & $95+05$ & 843 \\
\hline
\end{tabular}

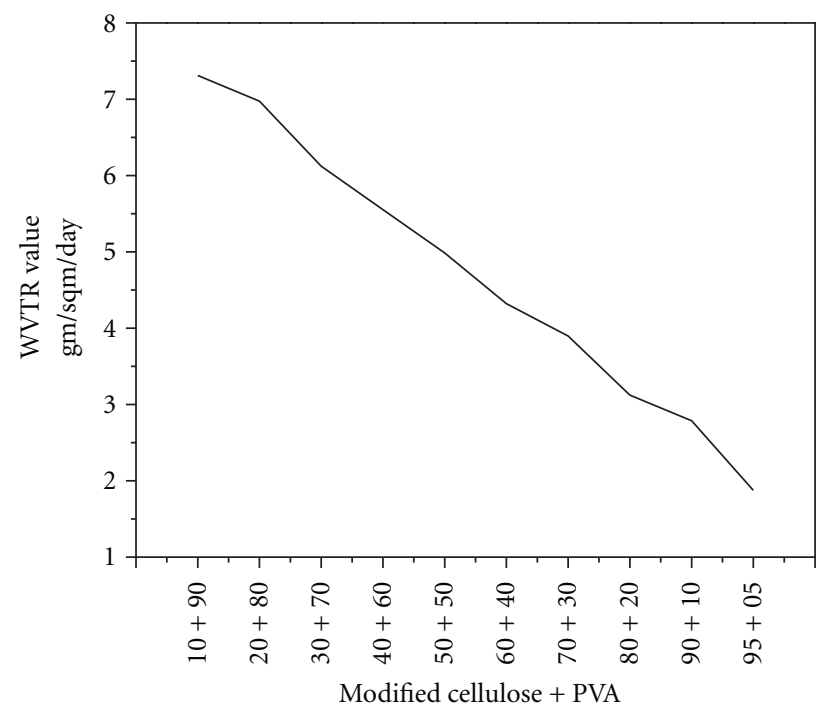

FIGURE 5: Variation of WVTR value for different film composites.

The comparison between OTR and WVTR indicates that modified cellulose is greatly effective in obstructing the oxygen permeation, but less effective in retarding the water vapor permeation. Figure 5 represents variation of water vapour permeation rate for all the ten films as the ratio of modified cellulose increases. This results show that these films may impede moisture transfer between the surrounding atmosphere and food or between two components of a heterogeneous food product. This property is very much usefull in packaging application.

3.6. Morphology. SEM micrographs $[24,25]$ of the film composites are shown in Figure 6. SEM micrographs were taken for four film composites in different magnification.

Figure 6(a) corresponds to 10:90 (modified cellulose + PVA) ratio film composite. In this figure, fibre is less visible due to poor dispersion of the reinforcement within the polymeric matrix, since composition of modified cellulose is only $10 \%$, leading to the poor dispersion within the PVA. Figure 6(b) corresponds to $30: 70$ (modified cellulose + PVA) ratio film composite. In this figure, fibre is slightly more 


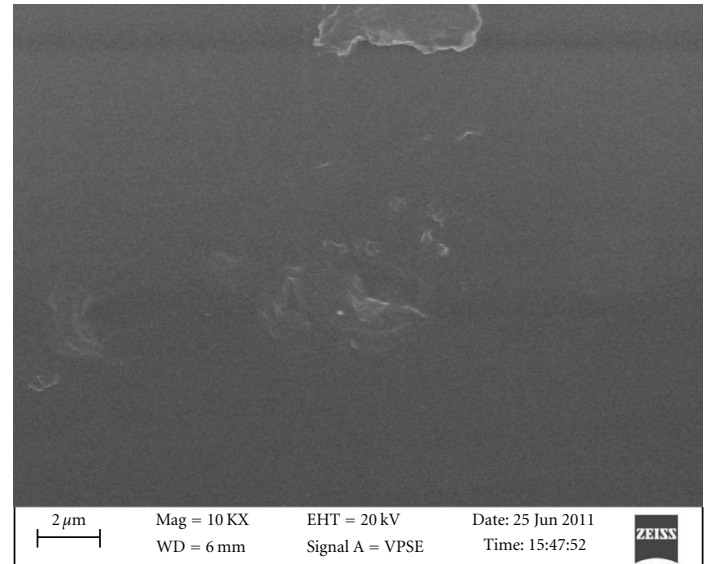

(a)

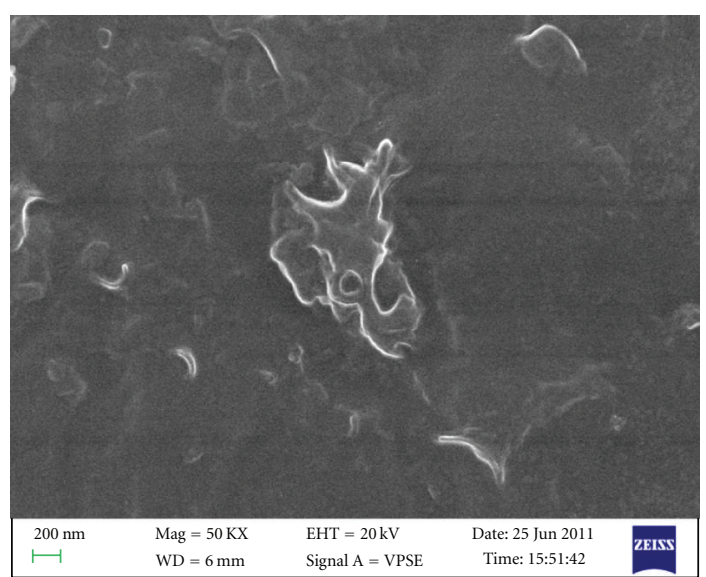

(c)

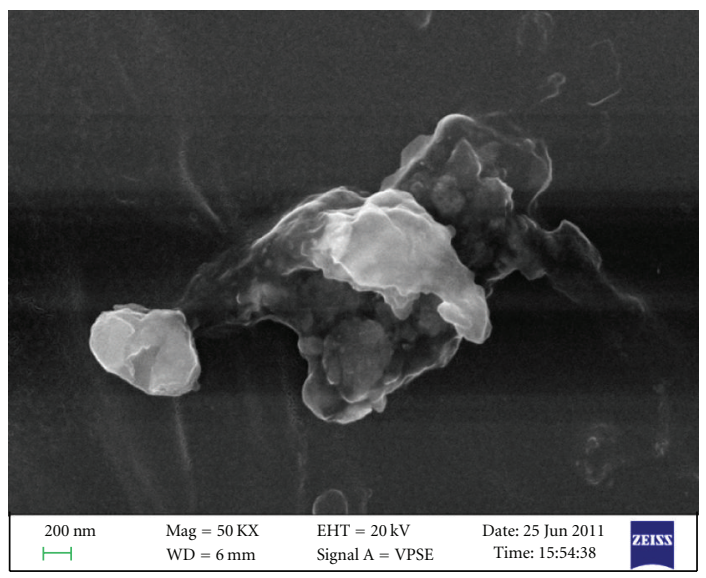

(e)

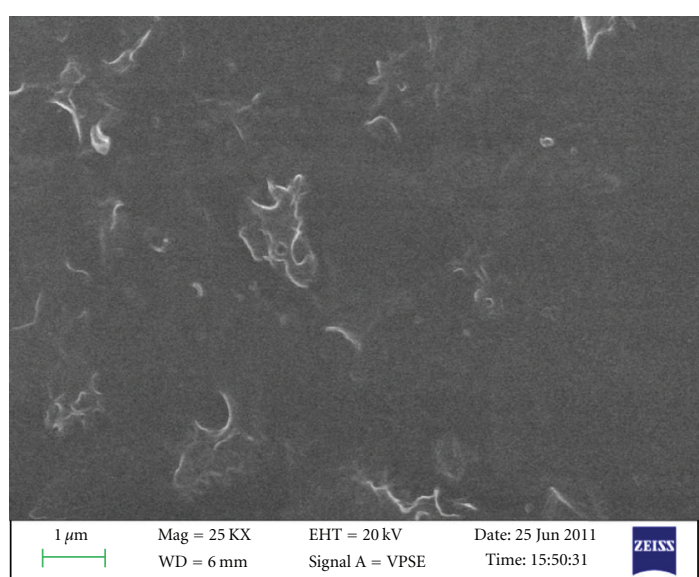

(b)

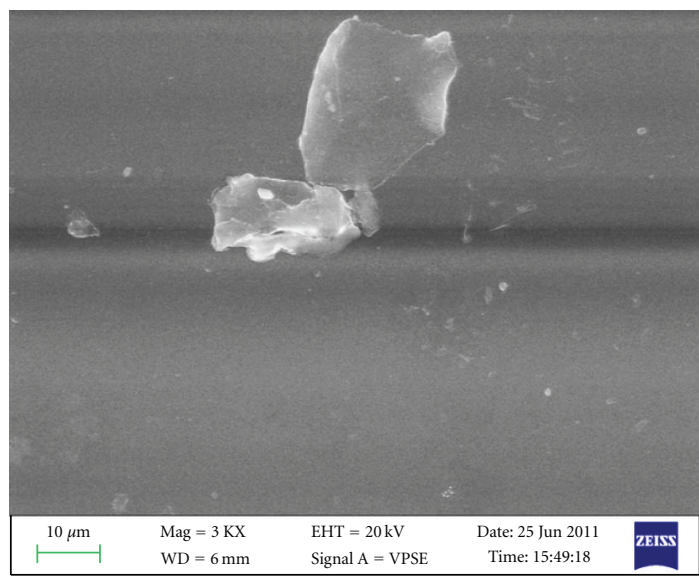

(d)

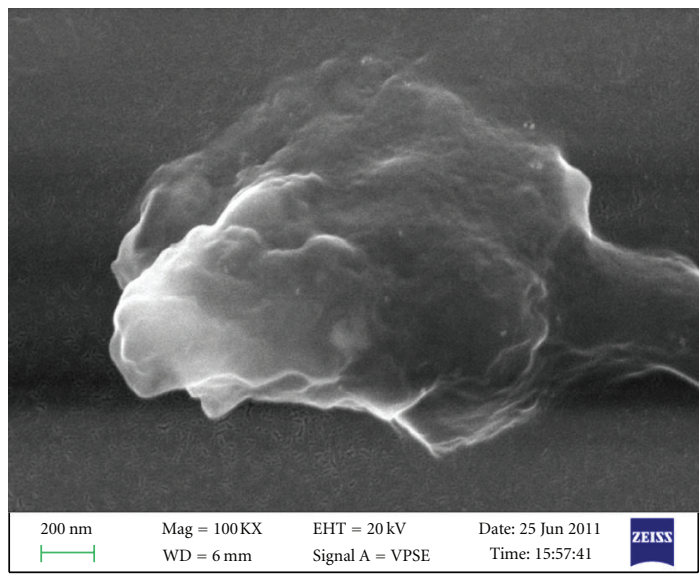

(f)

FIGURE 6: SEM microphotographs for (a) $10: 90$, (b) $30: 70$, (c) $50: 50$, (d) $70: 30$, (e) $80: 20$, (f) $90: 10$ film composites.

visible than before, since percentage of modified cellulose increased. Figure 6(c) corresponds to 50:50 (modified cellulose + PVA) ratio film composite which shows a better compatibility of the fibres with the matrix. In this figure, fibre is clearly visible and almost uniformly distributed. Figure 6(d) corresponds to 70:30 (modified cellulose + PVA) ratio film composite showing that fibre is trying to aggregate at one place due to the higher percentage of modified cellulose. However, the fibre pull-out length is not large, indicating a good fibre-matrix bonding. Figures 6(e) and 6(f) correspond to $80: 20$ (modified cellulose + PVA) and $90: 10$ (modified cellulose + PVA) ratio film composites, respectively, indicating the domination of fibre over a polymeric matrix. In this connection, it can be argued that there is an 
TABLE 5: Water vapor permeation rate for ten different film composites.

\begin{tabular}{lcc}
\hline S. no. & Modified cellulose + PVA & WVTR value gm/sqm/day \\
\hline 1 & $10+90$ & 7.312 \\
2 & $20+80$ & 6.976 \\
3 & $30+70$ & 6.123 \\
4 & $40+60$ & 5.554 \\
5 & $50+50$ & 4.986 \\
6 & $60+40$ & 4.321 \\
7 & $70+30$ & 3.897 \\
8 & $80+20$ & 3.123 \\
9 & $90+10$ & 2.786 \\
10 & $95+05$ & 1.876 \\
\hline
\end{tabular}

improvement of interfacial strength in the film composite as the percentage composition of modified cellulose increases.

\section{Conclusion}

We have successfully prepared biodegradable film composites using modified cellulose fibre-reinforced with poly(vinyl alcohol). Film composites produced by this method show very good biodegradation behaviour. This renders them advantageous in terms of environmental protection. Moisture absorption results show that modified cellulose plays great role in increasing the composite properties such as mechanical properties, since the proportion of modified cellulose increases, water uptake by the film composite was less. The produced film composites possess higher tensile strength as the proportion of modified cellulose increases and higher elongation at break as the proportion of PVA increases. So, modified cellulose plays vital role in increasing the tensile strength of film composites. OTR and WVTR test values show that modified cellulose plays powerful role in increasing the gas barrier properties. Hence these films can be used as a packaging to protect food from oxidation reaction and moisture.

\section{Acknowledgments}

The authors would like to acknowledge the great support by Post-Graduate Department of Studies and Research in polymer science, Sir, M. V. PG Centre, University of Mysore, Mandya, Karnataka, India, and Post-Graduate Department of Studies and Research in chemistry, Mangalore University, Mangalagangothri, Mangalore, Karnataka, India.

\section{References}

[1] P. R. Salgado, V. C. Schmidt, S. E. Molina Ortiz, A. N. Mauri, and J. B. Laurindo, "Biodegradable foams based on cassava starch, sunflower proteins and cellulose fibers obtained by a baking process," Journal of Food Engineering, vol. 85, no. 3, pp. 435-443, 2008.

[2] W. Liu, M. Misra, P. Askeland, L. T. Drzal, and A. K. Mohanty, "Green composites from soy based plastic and pineapple leaf fiber: fabrication and properties evaluation," Polymer, vol. 46, no. 8, pp. 2710-2721, 2005.

[3] K. G. Satyanarayana, G. G. C. Arizaga, and F. Wypych, "Biodegradable composites based on lignocellulosic fibers-an overview," Progress in Polymer Science, vol. 34, no. 9, pp. 9821021, 2009.

[4] R. L. Wu, X. L. Wang, F. Li, H. Z. Li, and Y. Z. Wang, "Green composite films prepared from cellulose, starch and lignin in room-temperature ionic liquid," Bioresource Technology, vol. 100, no. 9, pp. 2569-2574, 2009.

[5] S. Boufi and M. N. Belgacem, "Modified cellulose fibres for adsorption of dissolved organic solutes," Cellulose, vol. 13, no. 1, pp. 81-94, 2006.

[6] J. Zhang, N. Jiang, Z. Dang, T. J. Elder, and A. J. Ragauskas, "Oxidation and sulfonation of cellulosics," Cellulose, vol. 15, no. 3, pp. 489-496, 2008.

[7] Y. Kitkulnumchai, A. Ajavakom, and M. Sukwattanasinitt, "Treatment of oxidized cellulose fabric with chitosan and its surface activity towards anionic reactive dyes," Cellulose, vol. 15, no. 4, pp. 599-608, 2008.

[8] D. Pasquini, E. Teixeira, A. A. Curvelo, M. N. Belgacem, and A. Dufresne, "Surface esterification of cellulose fibres: processing and characterisation of low-density polyethylene/cellulose fibres composites," Composites Science and Technology, vol. 68, no. 1, pp. 193-201, 2008.

[9] S. Majumdar and B. Adhikari, "Polyvinyl alcohol-cellulose composite: a taste sensing material," Bulletin of Materials Science, vol. 28, no. 7, pp. 703-712, 2005.

[10] S. C. M. Fernandes, C. S. R. Freire, A. J. D. Silvestre et al., "Transparent chitosan films reinforced with a high content of nanofibrillated cellulose," Carbohydrate Polymers, vol. 81, no. 2, pp. 394-401, 2010.

[11] J. P. Borges, M. H. Godinho, A. F. Martins, A. C. Trindade, and M. N. Belgacem, "Cellulose-based composite films," Mechanics of Composite Materials, vol. 37, no. 3, pp. 257-264, 2001.

[12] L. Avérous, C. Fringant, and L. Moro, "Plasticized starch-cellulose interactions in polysaccharide composites," Polymer, vol. 42, no. 15, pp. 6565-6572, 2001.

[13] D. Plackett, T. L. Andersen, W. B. Pedersen, and L. Nielsen, "Biodegradable composites based on L-polylactide and jute fibres," Composites Science and Technology, vol. 63, no. 9, pp. 1287-1296, 2003.

[14] S. Ifuku, M. Nogi, K. Abe, K. Handa, F. Nakatsubo, and H. Yano, "Surface modification of bacterial cellulose nanofibers for property enhancement of optically transparent composites: dependence on acetyl-group DS," Biomacromolecules, vol. 8, no. 6, pp. 1973-1978, 2007.

[15] P. Gatenholm, J. Kubat, and A. Mathiasson, "Biodegradable natural composites-I. Processing and properties," Journal of Applied Polymer Science, vol. 45, no. 9, pp. 1667-1677, 1992.

[16] S. Ochi, "Development of high strength biodegradable composites using Manila hemp fiber and starch-based biodegradable resin," Composites A, vol. 37, no. 11, pp. 1879-1883, 2006.

[17] N. Y. Abou-Zeid, A. I. Waly, N. G. Kandile, A. A. Rushdy, M. A. El-Sheikh, and H. M. Ibrahim, "Preparation, characterization and antibacterial properties of cyanoethylchitosan/cellulose acetate polymer blended films," Carbohydrate Polymers, vol. 84, no. 1, pp. 223-230, 2011.

[18] L. Liu, J. Yu, L. Cheng, and X. Yang, "Biodegradability of poly(butylene succinate) (PBS) composite reinforced with jute fibre," Polymer Degradation and Stability, vol. 94, no. 1, pp. 90 94, 2009.

[19] J. Gassan and A. K. Bledzki, "Effect of moisture content on the properties of silanized jute-epoxy composites," Polymer Composites, vol. 18, no. 2, pp. 179-184, 1997. 
[20] C. Asasutjarit, S. Charoenvai, J. Hirunlabh, and J. Khedari, "Materials and mechanical properties of pretreated coir-based green composites," Composites B, vol. 40, no. 7, pp. 633-637, 2009.

[21] Y. Cao, S. Shibata, and I. Fukumoto, "Mechanical properties of biodegradable composites reinforced with bagasse fibre before and after alkali treatments," Composites A, vol. 37, no. 3, pp. 423-429, 2006.

[22] A. B. Dias, C. M. O. Müller, F. D. S. Larotonda, and J. B. Laurindo, "Mechanical and barrier properties of composite films based on rice flour and cellulose fibers," LWT-Food Science and Technology, vol. 44, no. 2, pp. 535-542, 2011.

[23] R. Ali, S. Iannace, and L. Nicolais, "Effect of processing conditions on mechanical and viscoelastic properties of biocomposites," Journal of Applied Polymer Science, vol. 88, no. 7, pp. 1637-1642, 2003.

[24] M. D. Sanchez-Garcia, E. Gimenez, and J. M. Lagaron, "Morphology and barrier properties of solvent cast composites of thermoplastic biopolymers and purified cellulose fibers," Carbohydrate Polymers, vol. 71, no. 2, pp. 235-244, 2008.

[25] C. J. Grande, F. G. Torres, C. M. Gomez, O. P. Troncoso, J. Canet-Ferrer, and J. Martinez-Pastor, "Morphological characterisation of bacterial cellulose-starch nanocomposites," Polymers and Polymer Composites, vol. 16, no. 3, pp. 181-185, 2008. 

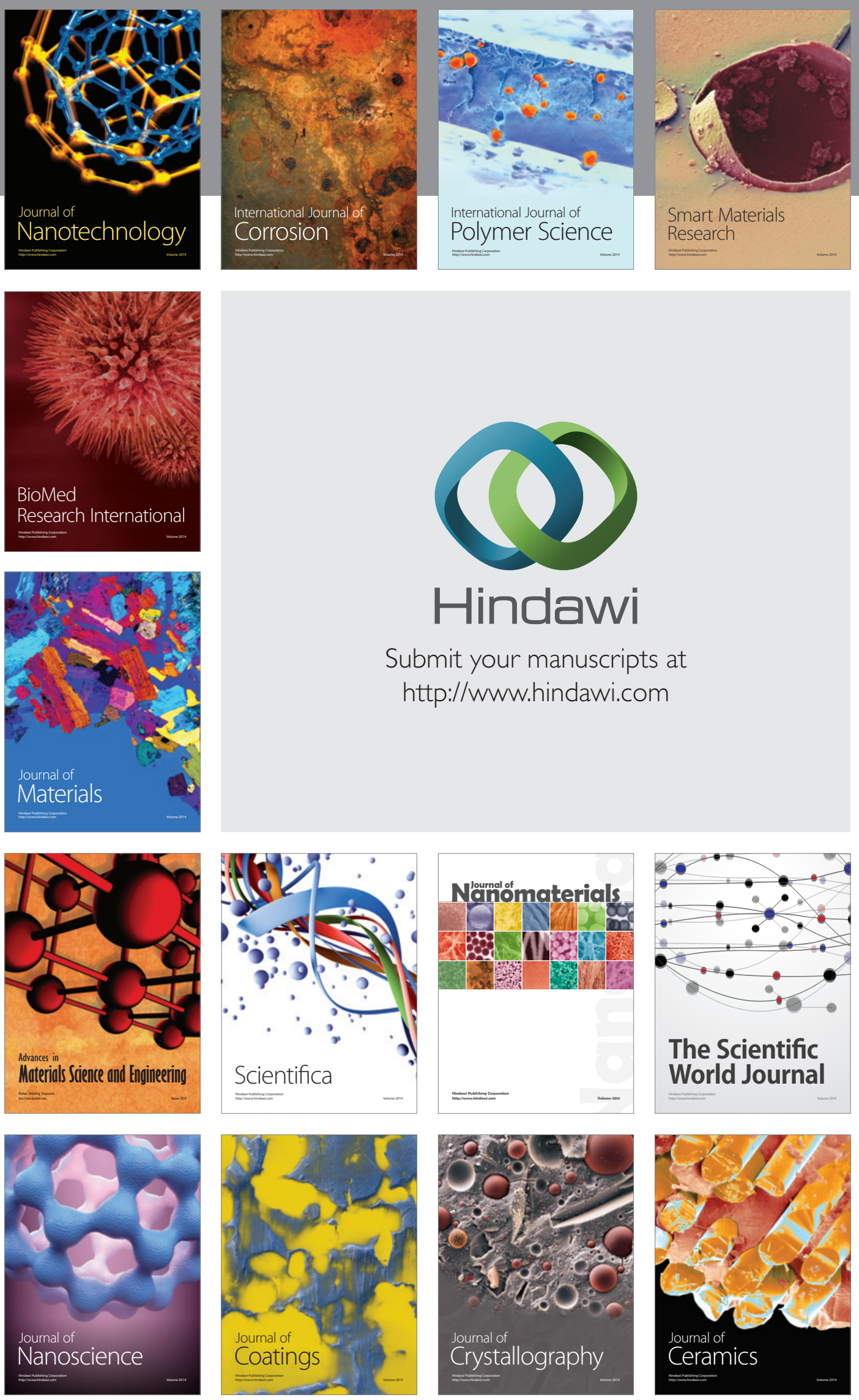

The Scientific World Journal

Submit your manuscripts at

http://www.hindawi.com

\section{World Journal}

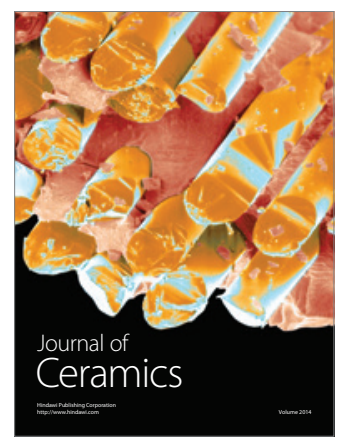

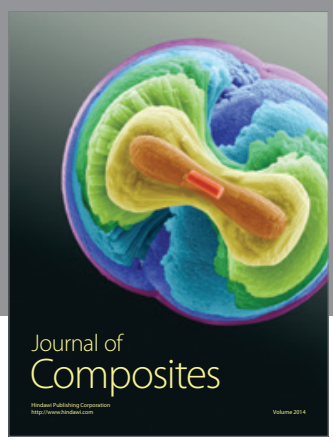
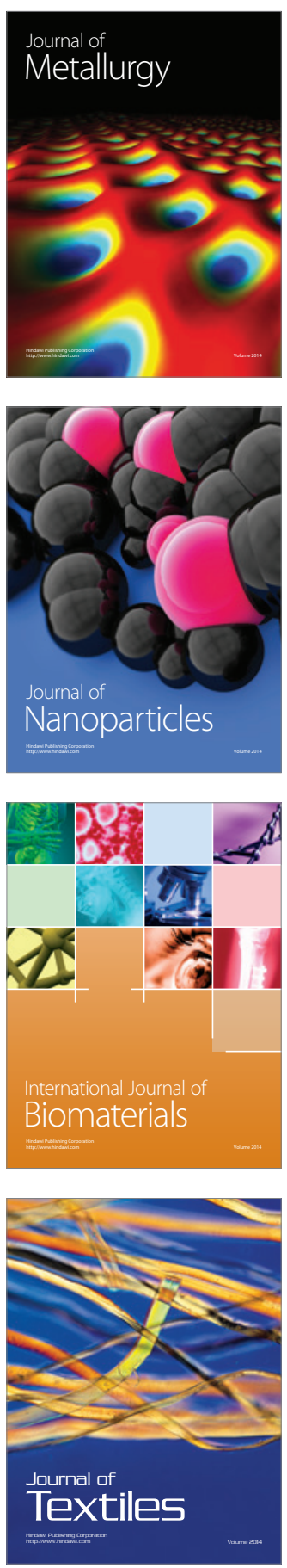